\title{
Evaluating web-based static, animated and interactive maps for injury prevention
}

\author{
Jonathan Cinnamon ${ }^{1}$, Claus Rinner ${ }^{2}$, Michael D. Cusimano ${ }^{3}$, Sean Marshall ${ }^{3}$, Tsegaye \\ Bekele $^{3}$, Tony Hernandez 2 , Richard H. Glazier ${ }^{4}$, Mary L. Chipman ${ }^{5}$ \\ ${ }^{1}$ Department of Geography, Simon Fraser University, 8888 University Drive, Burnaby, BC, Canada, V5A \\ 1S6; ${ }^{2}$ Department of Geography, Ryerson University, 350 Victoria St, Toronto, ON, Canada, M5B 2K3; \\ ${ }^{3}$ Injury Prevention Research Office, Keenan Research Centre, Li Ka Shing Knowledge Institute, St. \\ Michael's Hospital, University of Toronto, 2 Queen Street East, Toronto, ON, Canada, M5C 3G7; ${ }^{4}$ Centre \\ for Research on Inner City Health, St. Michael's Hospital, 70 Richmond Street East, Toronto, ON, Canada, \\ M5C 1N8; ${ }^{5}$ Dalla Lana School of Public Health, University of Toronto 155, College Street, Health Sciences \\ Building, Toronto, ON, Canada, M5T 3M7
}

\begin{abstract}
Public health planning can benefit from visual exploration and analysis of geospatial data. Maps and geovisualization tools must be developed with the user-group in mind. User-needs assessment and usability testing are crucial elements in the iterative process of map design and implementation. This study presents the results of a usability test of static, animated and interactive maps of injury rates and socio-demographic determinants of injury by a sample of potential end-users in Toronto, Canada. The results of the user-testing suggest that different map types are useful for different purposes and for satisfying the varying skill level of the individual user. The static maps were deemed to be easy to use and versatile, while the animated maps could be made more useful if animation controls were provided. The split-screen concept of the interactive maps was highlighted as particularly effective for map comparison. Overall, interactive maps were identified as the preferred map type for comparing patterns of injury and related socio-demographic risk factors. Information collected from the user-tests is being used to expand and refine the injury web maps for Toronto, and could inform other public health-related geo-visualization projects.
\end{abstract}

Keywords: injury, web mapping, geographical information system, public health, user-centred design, usability-testing.

\section{Introduction}

Geospatial data exploration and visual analysis can be used to inform public health research, planning and decision-making. Public health organizations are increasingly harnessing geospatial technologies to aid in decision support for a broad range

\footnotetext{
Corresponding author:

Jonathan Cinnamon

Department of Geography

Simon Fraser University

8888 University Drive, Burnaby, BC, Canada, V5A 1 S6

Tel. +1 778782 4987; Fax +1 7787825841

E-mail: jca80@sfu.ca
}

of purposes, including disease surveillance, health services allocation and for targeting health promotion initiatives. As public health datasets become increasingly complex, there is a growing need for methods and tools to support the construction of knowledge (Bhowmick et al., 2008). Despite the obvious benefits of maps that are easy to use and understand, limited guidance exists addressing how to actually design simple, functional, geographic visualization tools for use in the public health realm (Robinson et al., 2005).

The present study addresses this need by describing a crucial step in the iterative process of map and geo-visualization tool design: the testing of a proto- 
type web map site with a sample of public health stakeholders. Web-based static, animated and interactive maps of injury and related census variables were evaluated by potential users in injury research and prevention planning in Toronto, Canada. The study illuminated important issues regarding the design, utility and potential uses of different online map types, and could provide useful information for health organizations that wish to develop a webbased mapping system.

The following section discusses previous work in the area of health disparity, the epidemiology of injury, the use of maps in public health, public health informatics, user-centred design and usertesting. The "Materials and methods" section describes the functional and cartographic design elements of the three types of injury and socio-demographic maps, and the experimental procedure employed to test their usability and utility. The "Results" section summarizes the findings of the user-test, while the final section provides a discussion of the outcomes, future research directions and overall conclusions of the study.

Social disparity, health inequality, and place of residence

Cities are becoming increasingly segregated by income. Disadvantaged areas of a city are more likely to have residents reporting higher levels of poor health and well-being (Pevalin, 2007). There is substantial evidence that neighbourhood income levels exert an independent effect on individual health (Hou and Myles, 2005). Furthermore, the utilization of medical services and access to health care are strongly related to the socio-economic background of the individual (Petridou and Tursz, 2001). A study by Dunlop et al. (2000) found that, despite the existence of universal health care in Canada, citizens with lower incomes and fewer years of schooling visit health care specialists at a lower rate than those with moderate or high incomes and higher levels of education attained.

The socio-economic status (SES) of neighbour- hoods may influence the health of an individual to a greater degree than that of personal SES (Braveman et al., 2005). It has been argued that focusing on community strategies that concentrate on reducing risks for everyone rather than just searching for high-risk individuals will have a better overall impact on health (Curtis, 2004). As a result of these relationships between the demographic characteristics of neighbourhoods and health inequality, investigations are required into health disparities between neighbourhoods of low, average and high income (Lemstra et al., 2006).

\section{Injury and its socio-demographic determinants}

The rate of exposure to hazards is not shared equally between social groups. This has led to the description of the "risk society" paradigm, a reinterpretation of the idea of the "class society", where inequality is now defined by individual exposure to hazards (Beck, 1992; Curtis, 2004). This can be illustrated through exposure to health hazards, such as the variation in the risk of an individual sustaining an injury by income status, age, employment, and level of education. These socio-demographic factors exert their impact on the risk of sustaining an injury either by modifying human behaviour, or by increasing the occurrence and intensity of exposure to injury hazards (Petridou and Tursz, 2001).

SES is a predictor of morbidity and mortality for most types of injury, and can be a predictor for the related long-term outcome (Bradley and Harrison, 2003; Moshiro et al., 2005). Low income has been identified as a risk factor for various injury types including burns (Forjuoh, 2006), and self-inflicted injuries (Zhang et al., 2005). Age is also a determinant for many types of injury. For example, youths are often at highest risk for motor vehicle injuries (Houez et al., 1991) and the elderly are at a greater risk of suffering fall injuries than other age groups. One in four people aged over 65 years will sustain some sort of fall injury in a given year (Tinetti et al., 1994). Unemployment has been shown to be a factor in motor-vehicle related and self-inflicted 
injuries (Platt et al., 1992; Beautrais, 2000; LaScala et al., 2000). Also certain professions are associated with injury. Thus, it is generally believed that manual workers, as a result of the inherent occupational hazard, have a higher risk of sustaining injury than many other professions. Breslin et al. (2007a) found much higher relative risk values for youths employed in construction and labouring than those working in managerial and clerical positions, while occupations in the trades and manufacturing sectors were singled out in a study by Guidotti (1995). Poorly educated populations have been linked to injury in several studies. Zhang et al. (2005) discovered low education levels to be associated with suicide in women especially, while Beautrais (2000) linked high suicide rates with young people who had dropped out of school.

\section{Map-use in public health}

Public health informatics is the systematic application of information and communication technologies to support public health research and practice (Friede et al., 1995; Kukafka and Yasnoff, 2007). This approach has gained importance in recent years as technology has become both pervasive and indispensable in all aspects of health and medicine (Detmer, 2003). The scope of public health informatics includes the conceptualization, design, development, refinement and evaluation of public health surveillance and information systems (Yasnoff et al., 2000). Mapping and geographic visualization tools are increasingly being integrated into public health information systems, mirroring the rapid uptake in recent years of geographical information systems (GIS) and spatial analysis for decision-support in public health. Health organizations, governments, community groups and other public health stakeholders have used maps and geo-visualization technologies to contribute to their strategies for health promotion, prevention and control. For example, the Public Health Agency of Canada now provides GIS services such as the creation of maps and spatial analysis tools for public health professionals to "support the spatial information needs of evidencebased public health planning and research" (Public Health Agency of Canada, 2007). Human health studies have used GIS and mapping to examine the distribution of disease (Chen et al., 2008; Crighton et al., 2008), injury (Yiannakoulias et al., 2003; Breslin et al., 2007b; Schuurman et al., 2009), seeking determinants and studying risk factors (Ali et al., 2002; Scoggins et al., 2004; Younus et al., 2007; Reimers et al., 2008; Wang et al., 2009) and the effectiveness of disease control policies (CastilloRiquelme et al., 2008). However, despite their applicability in public health, maps and geographic visualization tools are still under-used (AbdelMalik et al., 2008; Bhowmick et al., 2008).

Web-based mapping has become an important means of map distribution in recent years, and is now the most frequent method of map dissemination (Peterson, 2003). Importantly, the Internet allows organizations to share, publish and distribute data and maps quickly and efficiently (Cromley and McLafferty, 2003). There are three types of maps found on the Internet; static, interactive and animated (Peterson, 2003). Static maps provide little functional benefit over paper maps, animated maps allow for a time series or variable change, while interactive maps allow for user-interaction through changing the display in some manner. Increasingly, health organizations have maps of all types available on their web sites, some of which are targeted at a public audience, while other maps are for the exclusive use of public health professionals. In the past, small health and community organizations were restricted from introducing GIS tools into their agenda, often as a consequence of expertise and resource deficiencies (Maclachlan et al., 2007). In recent years, webbased GIS and interactive maps have materialized as a solution for providing access to useful geospatial information for larger audiences with often limited GIS experience (Kamadjeu and Tolentino, 2006; Pfeiffer et al., 2008). Web-GIS and online interactive maps are often designed to be more user-friendly and simpler than desktop GIS systems, and can also be created and maintained at a lower cost. 


\section{Usability engineering and user-testing}

Novel methods for visualizing geospatial data have been developed in conjunction with the rapid advancements in hardware and software in recent years. This has elicited questions regarding the relationship between the user, the technology and the developer such as:

(i) Are new geo-visualization methods appropriate for the target user-group?

(ii) Are they useful for the user's purposes?

(iii) How can the user contribute to the design of new technologies?

(iv) What level of user-needs assessment is required?

The user-centred design (UCD) process attempts to ensure that this type of questions is addressed during technology development. UCD considers the end-user at all stages of development to ensure that technology is appropriate, functional and useful to complete tasks (Bowen and Reeves, 2007). Better geo-visualization tools can be created through a usability approach and with knowledge of cognitive processes (Slocum et al., 2001). This can result in the creation of new technologies that are both easy to learn and also increase productivity and, as a result, increase user-acceptance. The early involvement of potential users and an iterative cycle of interaction between users and designers of tools are core principles of UCD, with the purpose of developing tools that are useful and appropriate for the target domain (Bhowmick et al., 2008).

Developers of technology for health often overlook important user-characteristics, tasks, preferences and usability concerns, resulting in systems that generate more confusion than benefits, or simply remain inadequate (Johnson et al., 2005; Timpka et al., 2008). As a result, health policy makers are now demanding evidence to justify investments in health information systems (Kushniruk and Patel, 2004). A study by Johnson et al. (2005) documented the re-design of a difficult-to-use health care information system into a new system that showed significant improvements in usefulness, information quality and interface quality. This re- design was based on principles of user-centred design. Also, Robinson et al. (2005) created "ESTAT", an exploratory geo-visualization toolkit for epidemiological research based on usability techniques and UCD. This process of involving potential users allowed the authors to design a tool that was better suited to the tasks of epidemiology.

Usability-testing refers to the evaluation of information systems with participants who are representative of the target user-population, as they interact with an information technology (Kushniruk and Patel, 2004). This is now seen as an essential aspect of software design, testing, implementation, acceptance and uptake (Norman and Panizzi, 2006). It is crucial to the development of new geo-visualization tools as it promotes a convergence of the user, the technology and the developer. Test results can help uncover problems associated with user-comprehension or just simple design flaws that were previously unnoticed by the developer. They are also an effective way to determine if the target user finds the tool useful for their needs. Users can be tested together in a group setting, or in individual sessions. One-on-one testing is preferred as it avoids pitfalls related to group dynamics. Individual tests can take the form of task completion scenarios, developer-led walkthroughs or self-administered testing (Norman and Panizzi, 2006). The "think aloud" method is often used during these sessions whereby the user vocalises their movements around the interface, including any problems, questions or comments they may have (Jaspers et al., 2004). Testing sessions can be recorded by video or audio if in-depth analysis of the users' movements and comments is necessary, while a questionnaire or discussion at the end of the session can be useful to complement in-test comments. The majority of usability issues can often be highlighted from a representative sample which typically involves as few as 8-10 participants (Kushniruk, 2002).

User-testing has been useful for creating and implementing web-based mapping systems appropriate for public health users. A study by Maclachlan et al. (2007) documented the development of a web-based 
interactive tool designed to investigate the relationship between asthma, air quality, and socio-demographic factors in Hamilton, Ontario in Canada. Upon completion of the tool in this study, a focus group and user-test of end users was assembled to assess usability and functionality of the online tool. The session took the form of a group session with presentations related to the topic, after which the users could explore the tool. The users tested the tool under the supervision of assistants who were there to answer questions if necessary. A survey was submitted at the end of the session.

Several studies have compared static maps with animated maps. The objectives of these studies included determining which type was more appropriate for facilitating the users' ability to recognise spatially distributed phenomena, and also comparison testing for usability and utility between the two map types (Kossoulakou and Kraak, 1992; Griffin et al., 2006). A study by Slocum et al. (2004) found that map animations and static maps were useful for completing different tasks. Animations were better for identifying general trends, while static maps were best for comparing specific time points.

The purpose of the present study was to determine whether static, animated or interactive maps are preferred by public health users, and to assess their overall usability and utility with that particular usergroup. The three map types were created using injury and socio-demographic data for the city of Toronto, Canada. These user-tests represent a critical stage in the development of geographic visualization tools. An additional purpose of the study was to describe the iterative map-development protocol which could be used for the creation of similar maps and geographic visualization tools for use within the public health domain. No studies have been found that directly test static, animated and interactive maps for usability and utility with end-users. Also, little has been written about designing maps for public health users specifically. The present research contributes to map-type comparison research, webbased mapping and geo-visualization for public health applications.

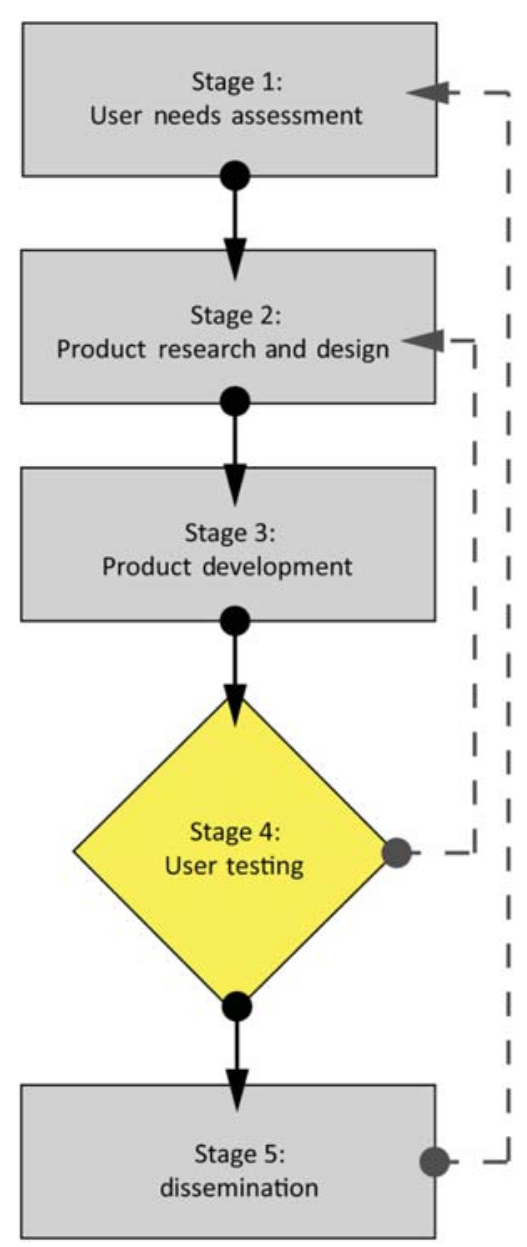

Fig. 1. Iterative process of map development used in the present study.

\section{Materials and methods}

User-testing as a critical stage in map development

The design of the maps followed an iterative process as shown in Figure 1, adapted from other studies of software and geo-visualization tool development based on user-needs (e.g. Kushniruk, 2002; Slocum et al., 2003; Robinson et al., 2005). An initial assessment of user-needs (stage 1) arose from a series of meetings in which public health stakeholders described a need for maps and tools to examine 
spatial patterns of injury and related determinants. The research and design and the map development (stages 2 and 3) followed. The three map types were developed based on the needs assessment, a review of maps available on public health web sites and common cartographic principles. For a complete description of the needs assessment, map design, and web site development, the reader is referred to Cinnamon et al. (in press). The present paper focuses on the user-testing phase (stage 4) in Figure 1, in which the static, animated and interactive maps of injury and its socio-demographic determinants were tested using a sample of public health officials and injury prevention stakeholders in Toronto. Participants were employees of provincial and municipal government, children and youth aid organizations and hospitals, as well as health practitioners.

\section{Data sets and map development}

The injury data set used was the Ontario Trauma Registry's (OTR) Minimal Data Set (MDS) for 2001 to 2003, which records injury hospitalizations by place of residence. Four types of injuries were mapped: fall, motor vehicle and traffic, intentional and "other injuries". The intentional category includes assault, homicide, suicide and self-inflicted injury. The "other injury" category includes nonintentional injuries that did not fit any other category. The census for 2001 from Statistics Canada provided the data to create the socio-demographic maps. The maps were created based on a selection of risk factors for injury as outlined above, including age groups at risk, level of education, income, employment status and occupation type. The choro-

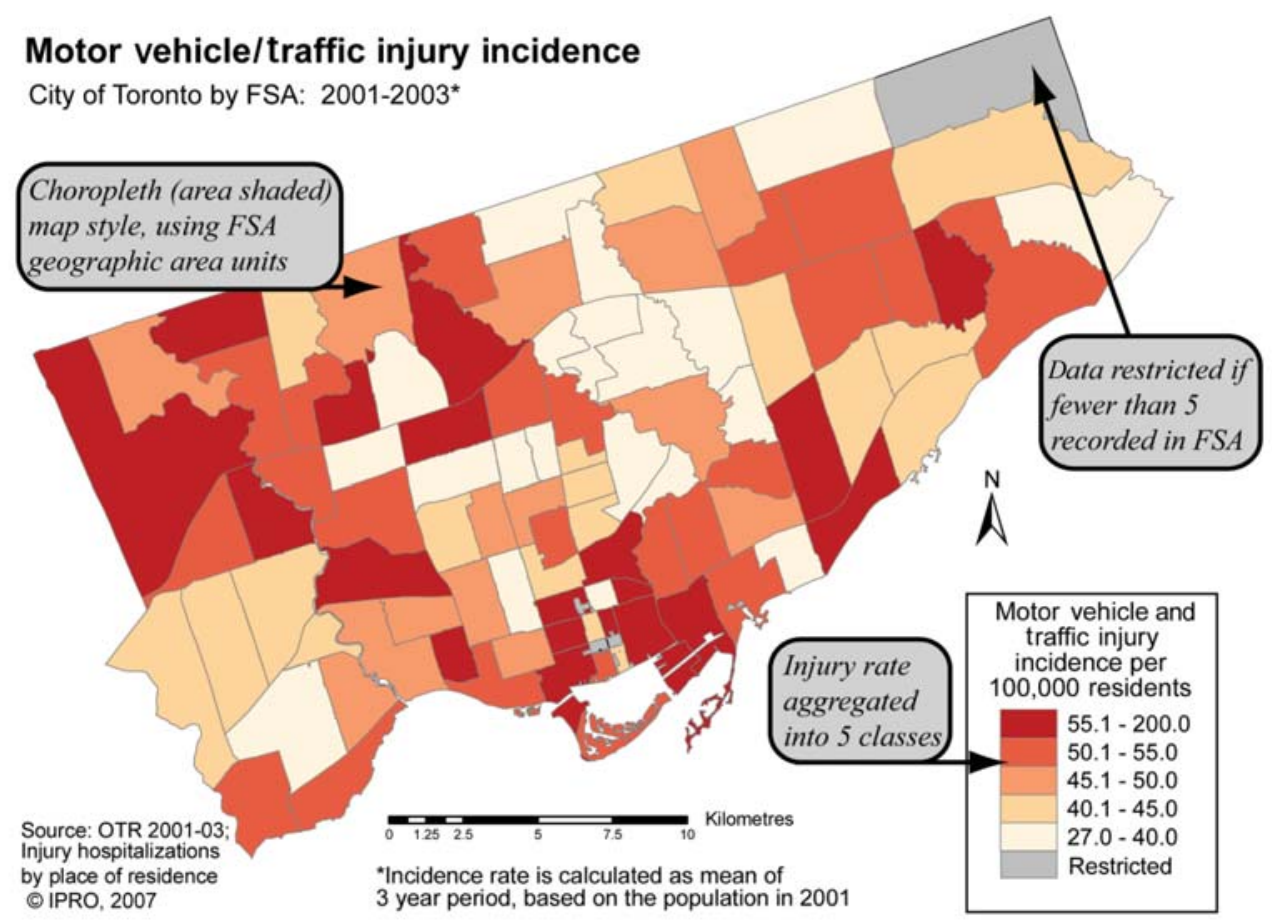

Fig. 2. Layout and cartographic design used for static, animated and interactive maps. All maps used the choropleth (area-shaded) style to represent the injury/socio-demographic data in each FSA as a rate per 100,000 residents. Data were aggregated into 5 classes, categorized into quintiles (an equal number of records in each class). Injury maps were created based on the place of residence of the injured person. FSA geographic units with fewer than five incidents were restricted for reasons of patient confidentiality. 
Table 1. Characteristics of the static, animated and interactive maps included in the user test.

\begin{tabular}{|c|c|c|c|c|}
\hline Map type & Viewing options & Elements and functions & Level of interaction & Maps included in user-test \\
\hline Static maps & Onscreen or print & $\begin{array}{l}\text { Display spatial attributes } \\
\text { Non-modifiable display }\end{array}$ & Low & $\begin{array}{l}8 \text { injury maps } \\
9 \text { socio-demographic maps }\end{array}$ \\
\hline Animated maps & Onscreen only & $\begin{array}{l}\text { Observe dynamic geographic } \\
\text { phenomena } \\
\text { Examine change by time-series or } \\
\text { variable }\end{array}$ & Medium & $\begin{array}{l}2 \text { time series animations (months, } \\
\text { year) } \\
1 \text { injury type animation } \\
1 \text { socio-demographic variable ani- } \\
\text { mation }\end{array}$ \\
\hline Interactive maps & Onscreen only & $\begin{array}{l}\text { Non-modifiable } \\
\text { Display spatial attributes } \\
\text { User-modified display } \\
\text { Map comparison } \\
\text { Pan, zoom } \\
\text { Layer change }\end{array}$ & High & $\begin{array}{l}8 \text { injury map layers } \\
9 \text { socio-demographic map layers } \\
\text { Roads and highways layer }\end{array}$ \\
\hline
\end{tabular}

pleth mapping technique was used for all maps based on the Forward Sortation Area (FSA), a Canadian postal code geographic unit, for the city of Toronto (see Fig. 2). Both the injury and sociodemographic data were mapped as rates per 100,000 residents.

A web site was developed as a portal to disseminate the static, animated and interactive maps of injury and related socio-demographic determinants. Table 1 describes the elements, features and functions of the three map types included in the web site. Eight static injury maps and nine socio-demographic maps were created. Four animation types were created which combined the static maps into single animation files with multiple frames: by month (12 frames), by year (3 frames), by injury type (4 frames) and by socio-demographic variable $(8$ frames). These animations used a fixed pace, which did not allow for pausing while the animation was running. An interactive map tool was created that allowed for a comparison of any injury or sociodemographic map on the same computer screen through a unique horizontally split-screen concept (see Fig. 3). The main purpose for employing this design was to allow the user to view, manipulate and compare two different maps at the same time, without creating excessive visual clutter. Confusion caused by visual complexity is a fact of many interactive mapping systems that allow for multiple layers to be viewed on top of each other. The interac- tive maps could be zoomed in or out separately by choosing a zoom level in a dropdown menu, and panning the maps was possible by clicking on the map itself. In addition, a major roads layer could be overlaid. A restricted version of the Toronto Injury Maps Web site is available to view at http://141.117.104.183/toronto_injury/, with the user-name "cartographica" and password "injurygis". Instructions for use of the maps were provided on the web site.

\section{Experimental procedure}

To test the maps available on the Toronto Injury Maps Web site, user-testing sessions were held during the months of July and August 2007. Eight participants from various public health related backgrounds participated in the study, each of whom had some background knowledge of injury-mapping through participation on an advisory board for an injury GIS research project. This was considered a representative sample of potential users of these maps. Each participant was tested individually at his or her workplace with two researchers administering the interviews. The developer of the maps and web site introduced the project and answered questions during the session. An assistant recorded the comments, questions and concerns of the participant at all stages of the interview, observing body movements and mannerisms of the user 


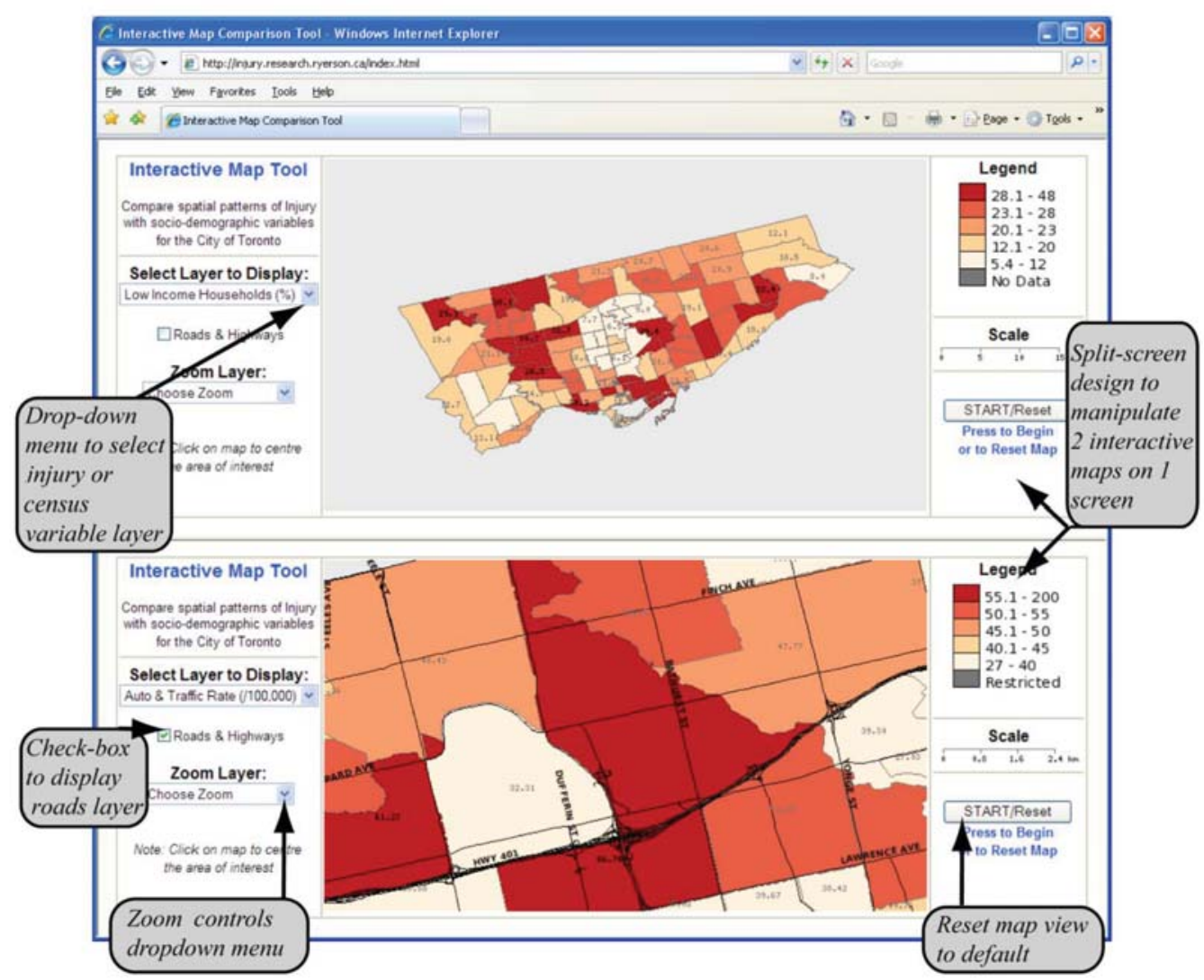

Fig. 3. Screenshot of the interactive map tool. A selection of injury and socio-demographic maps can be viewed and compared on the same screen using the split-screen feature. The interactive maps also feature zoom and pan capabilities, as well as the option to overlay a major roads layer on top of the maps to aid in place recognition.

while they interacted with the maps. The participants were encouraged to "think aloud" during the tests so the assistant could record their questions, and any problems they had with map-comprehension or navigation. At the end of the session a questionnaire was filled out by the participant, after which a short discussion was held so the user could discuss freely any related topics such as web-based mapping or the use of geospatial data in relation to public health. The questionnaire included structured and open-ended questions. A five-point "Likert scale" from strongly agree to strongly disagree was used for structured questions on general aptitude, broad questions on each of the map types, and potential use, limitations and overall satisfac- tion for all map types. The open-ended questions were designed to elucidate the participants' opinions regarding the most and the least useful map type, the benefits and limitations of each type, what changes and additions they believe are required, and their overall feelings regarding geo-visualization for public health. The open-ended questions immediately followed the fixed-choice questions related to the same topic and were designed to generate discussion about that aspect of usability. Each session was scheduled for one hour as it was believed this should be adequate time to navigate around the web site, view and compare map types, complete a questionnaire and discuss any related issues. 


\section{Results}

The responses to the five-point scale questions are shown in Table 2. In terms of general aptitude, all the participants used the Internet and computers on a regular basis. The participants were split on the question of whether they use geographic data regularly between strongly agree and disagree. This suggests that the sample included both, users with a strong background in geospatial data and analysis, and users new to the field. Two-thirds of respondents agreed that they have a good understanding of Internet map- ping, while half strongly agreed they have a good understanding of the geography of Toronto.

All the respondents either agreed or strongly agreed that the static maps were easy to understand. A majority also agreed or strongly agreed that the colour scheme used was easy to comprehend. Threequarters agreed or strongly agreed that the animations were easy to understand. Interestingly, the respondents were split over the usefulness of the time-series animation, while three-quarters agreed or strongly agreed that the variable animations (by injury type, by socio-demographic variable type)

Table 2. Results of the questionnaire ( $\mathrm{n}=8$ participants).

\begin{tabular}{|c|c|c|c|c|c|}
\hline Questionts & $\begin{array}{l}\text { Strongly agree } \\
(\%)\end{array}$ & $\begin{array}{l}\text { Agree } \\
(\%)\end{array}$ & $\begin{array}{l}\text { Nondecided } \\
(\%)\end{array}$ & $\begin{array}{l}\text { Disagree } \\
(\%)\end{array}$ & $\begin{array}{l}\text { Strongly disagree } \\
(\%)\end{array}$ \\
\hline \multicolumn{6}{|l|}{ General aptitude } \\
\hline I use computers regularly & 100 & 0 & 0 & 0 & 0 \\
\hline I use the Internet regularly & 100 & 0 & 0 & 0 & 0 \\
\hline I use geographic data regularly & 12.5 & 37.5 & 25 & 25 & 0 \\
\hline I have a good understanding of Internet mapping & 12.5 & 62.5 & 12.5 & 12.5 & 0 \\
\hline I have a good understanding of Toronto geography & 50 & 37.5 & 0 & 12.5 & 0 \\
\hline \multicolumn{6}{|l|}{ Type 1 (static) } \\
\hline The maps were easy to understand & 50 & 50 & 0 & 0 & 0 \\
\hline The colour scheme was easy to comprehend & 37.5 & 37.5 & 12.5 & 12.5 & 0 \\
\hline \multicolumn{6}{|l|}{ Type 2 (animated) } \\
\hline The animations were easy to understand & 37.5 & 50 & 12.5 & 0 & 0 \\
\hline The time series animations were useful & 37.5 & 25 & 25 & 12.5 & 0 \\
\hline The variable animations were useful & 37.5 & 50 & 12.5 & 0 & 0 \\
\hline \multicolumn{6}{|l|}{ Type 3 (interactive) } \\
\hline The tool was easy to use & 75 & 25 & 0 & 0 & 0 \\
\hline The layout was appealing & 75 & 12.5 & 12.5 & 0 & 0 \\
\hline The tool was intuitive & 50 & 37.5 & 12.5 & 0 & 0 \\
\hline The level of content was appropriate & 50 & 25 & 25 & 0 & 0 \\
\hline The functionality was useful (zoom/layer change) & 50 & 37.5 & 12.5 & 0 & 0 \\
\hline \multicolumn{6}{|l|}{ Potential use (all map types) } \\
\hline Data visualization & 75 & 25 & 0 & 0 & 0 \\
\hline Colleague collaboration & 50 & 37.5 & 12.5 & 0 & 0 \\
\hline Data exploration & 37.5 & 37.5 & 25 & 0 & 0 \\
\hline Decision support & 50 & 37.5 & 12.5 & 0 & 0 \\
\hline \multicolumn{6}{|l|}{ Limitations (all map types) } \\
\hline Limited data & 0 & 50 & 37.5 & 12.5 & 0 \\
\hline Time/cost involved to create & 0 & 12.5 & 75 & 12.5 & 0 \\
\hline Limited geographic knowledge of the user & 0 & 25 & 25 & 37.5 & 12.5 \\
\hline Difficult to use & 0 & 0 & 12.5 & 62.5 & 25 \\
\hline \multicolumn{6}{|l|}{ Overall satisfaction (all map types) } \\
\hline The maps were useful & 50 & 50 & 0 & 0 & 0 \\
\hline
\end{tabular}


were useful. The users had similar experiences with the interactive map tool. Three-quarters strongly agreed that the tool was easy to use and the layout was appealing. Most thought that the tool was intuitive, the functionality was useful and the level of content was appropriate.

The participants also had similar views regarding the potential use of the maps, with most agreeing or strongly agreeing they could be used for data visualization, collaboration, data exploration and decision support. There were more variable answers regarding the limitations of the maps. Half of the participants agreed that data could be a limitation, while three-quarters of them were undecided as to whether the time and cost to create was a limitation of the maps. The respondents were split as to whether the user's limited geographic knowledge would limit utilization of the maps. Most disagreed that difficult-to-use maps are a limitation. Finally, all test subjects agreed or strongly agreed that the maps were useful, and that they could improve work in injury prevention.

The open-ended questions further determined the participants' opinions regarding the usability and utility of each map type. A wide variety of responses was received. There was consensus that geo-visualization of both health and socio-demographic data can improve public health research. Several comments suggested that this type of mapping would directly improve decision making by helping to determine where scarce public health resources should be invested for injury prevention programmes. A question asking what changes or additions should be made to the maps received similar responses from all the participants. Mainly, they were concerned with having more data included, more specific injury types and more socio-demographic variables to compare.

When asked about the benefits and limitations of the static maps, two benefits noted frequently were that static maps are easy to use for people who are unfamiliar with map analysis, and that they are versatile because they can be viewed on-screen or as a printed version. A limitation noted with several respondents is that static maps are restrictive based on the fact that only one variable is shown on each map, therefore the user must switch back and forth on screen or in print to compare the distribution of different variable or injury types.

The majority of the participants agreed that the pace of the animations should be modifiable. Indeed most said that the frames changed too fast to read all the information, which made this a limitation of the animated maps. The main benefit of the animations for the participants was the ability to see trends over time both quickly and easily.

Few limitations were noted with the interactive map tool. The only limitations the users posited were related to functionality and layout. One user suggested a report creation capability or query function, while another suggested that there was too much information on a single screen. Many benefits of the interactive tool were noted. The ability to compare any of the maps on a single screen almost instantaneously via the use of the split-screen was a benefit for most respondents. It also was believed that patterns and relationships between the injuries and determinants are more visible when using this map type, as compared to the animations and static versions.

When asked what the most and least useful map types were, all of the respondents agreed that the interactive map was the most useful, though many also noted that each map type may be useful for different purposes. The animated maps were singled out as the least useful in two cases, the remainder of the respondents simply stated that they found all the map types to be useful.

During the session the users' comments, questions and general ability with the maps was noted by the assistant interviewer. Each participant varied in their ability to navigate the web site and interpret the maps. Some needed no instruction whatsoever, while others required guidance and an added tutorial beyond the explanation provided on the web pages. Surprisingly, some of the participants had substantial background knowledge of geo-visualization and web-based mapping, while some had very 
little knowledge of either. Some participants were able to make instant visual correlations using the interactive tool. For example, areas that had both high intentional injury rates and also a high proportion of low income households. Many also noticed high rates of injury in areas of the city which they have targeted for programming in their own public health area of specialization.

\section{Discussion}

This paper describes a user-test and comparison of web-based injury maps with a sample of public health stakeholders. The results have provided valuable insight into the particularities of map usability and the utility of different map types for that usergroup. Hedley (2001) has highlighted the importance of understanding new technologies and how they relate to end users in order to maximise their potential. A user-centred design approach aids technology development through collecting information which will help to better understand the users and their tasks and also the environment in which they work.

The user-sessions have helped to illuminate an important stage in geo-visualization tool design for the field of public health. Overall, interactive maps were identified as the preferred type for comparing patterns of injury and related socio-demographic risk factors while static and animated versions of the same maps were also judged as effective for visualizing the data for different purposes. These results suggest that end users will benefit from access to a selection of geo-visualization methods when analyzing geospatial data in their research. As web-based mapping systems are used by a wide variety of people with different background knowledge and purposes, a variety of choices should be available to them (Nivala et al., 2007).

Representing both health event and population data in public health research is crucial (Brabyn and Wilkins, 2001). A Canadian health surveillance information study identified access to current data on both health outcomes and risk factors as a prior- ity for new health information systems (Maclachlan et al., 2007). Therefore, when creating maps of a public health problem such as injury, it is essential to also create maps of the related determinants. The split-screen aspect of the interactive map tool was of particular interest to the users. Split screens for comparing two maps on a single screen has not been implemented elsewhere in online health mapping to the knowledge of the authors. Common methods of comparing multiple variables, such as map overlay, can result in obscured patterns and cluttering. The split-screen method (corresponding to traditional small multiples) was found to be an effective way to compare variables easily and interactively.

The information collected during the user-test is currently being applied to further develop webbased injury maps for Toronto. The interactive map prototype developed for this study will be refined using the process documented in this study through a return to the user-needs assessment and product research and design phases (stages 1 and 2). Based on the comments and suggestions, additional functions will be explored including map query and report capabilities and the addition of more variables to investigate. Also, more options for the animated maps could be helpful, including the ability to pause and change the pace. This iterative process is beneficial, although mapping applications are frequently put into use after the first round of usability testing, because they are often complicated to implement and difficult to modify after they have been developed (Nivala et al., 2007). The intention of this round of user-testing was to assemble information from the user-group regarding their needs and capabilities, which could then be fed into a more usable, functional and appropriate web-mapping system. The results presented here describe a method for map developers to determine what types of maps are appropriate for the needs of a particular end user-group. In addition, the findings have helped to uncover some characteristics of map use by public health stakeholders and could be useful for organizations that wish to engage in web-based mapping, whether for display on a public web site 
or for internal use within the organization.

A few limitations of the user-test were noted as follows. The FSA is an unusual unit of geography, particularly for the target end users who are more accustomed to seeing maps of Toronto delineated by census tracts or neighbourhoods. Using an "areal” unit that is familiar to the target audience is important (Boscoe and Pickle, 2003). However, using FSAs was unavoidable as the injury dataset was only available to be mapped at that level because of the data provider's concern for privacy issues. Another challenge stemmed from the fact that a wide range of public health users participated, since each user had different data needs based on the type of work they were involved in.

No options for pace change in the animated maps were considered at the outset of the study, and frame delay times were preselected for each animation. Griffin et al. (2006) found that participants identified clusters easier with longer frame delay times, though at a certain threshold the animations ceased to be useful. This suggests that providing interactive controls to manipulate the pace of the animations is critical so the viewer can make adjustments based on their own needs and visualization ability.

In summary, this study has helped to illuminate some important considerations for developing web-maps for use by public health stakeholders. Although the users had varying levels of expertise and knowledge of mapping and geo-visualization, the participants were enthusiastic about the study and about advancing web-based mapping for injury prevention and research. This study contributes to evaluating the use of geo-visualization for public health planning and decision-making. In addition to the use of the results to improve the Toronto injury mapping web site, future research may focus on assessing other cartographic and graphic visualization techniques that could be applied to public health. Also, an extended usertest with different profiles of end users and with control groups could be used to validate our observations.

\section{Acknowledgements}

Partial funding for this project was provided by the Natural Sciences and Engineering Research Council of Canada and the Canadian Institutes of Health Research. The data from the Ontario Trauma Registry were obtained through the injury GIS project. Parts of this material are based on data and information provided by the Ontario Trauma Registry and Ontario Ministry of Health and LongTerm Care. However, the analyses, conclusions, opinions and statements expressed herein are those of the authors, and not necessarily those of the Ontario Trauma Registry or the Ontario Ministry of Health and Long-Term Care.

\section{References}

AbdelMalik P, Boulos M, Jones R, 2008. The perceived impact of location privacy: a web-based survey of public health perspectives and requirements in the UK and Canada. BMC Public Health 8, 156.

Ali M, Emch M, Donnay JP, Yunus M, Sack RB, 2002. Identifying environmental risk factors for endemic cholera: a raster GIS approach. Health Place 8, 201-210.

Beautrais AL, 2000. Risk factors for suicide and attempted suicide among young people. Aust N Z J Psychiatry 34, 420-436.

Beck U, 1992. Risk society: towards a new modernity, SAGE, 260 pp.

Bhowmick T, Griffin AL, MacEachren AM, Kluhsman BC, Lengerich EJ, 2008. Informing geospatial toolset design: understanding the process of cancer data exploration and analysis. Health Place 14, 576-607.

Boscoe FP, Pickle LW, 2003. Choosing geographic units for choropleth rate maps, with an emphasis on public health applications. CaGIS 30, 237-248.

Bowen J, Reeves S, 2007. Formal models for informal GUI designs. E Notes Theor Comput Sci 183, 57-72.

Brabyn L, Wilkins D, 2001. Mapping health events - a comparison of approaches. Health Inform J 7, 207-213.

Bradley C, Harrison JE. 2003. Injury risk factors, attitudes and awareness: a submission to the CATI-TRG. Adelaide: AIHW.

Braveman PA, Cubbin C, Egerter S, Chideya S, Marchi KS, Metzler M, Posner S, 2005. Socioeconomic status in health 
research: one size does not fit all. JAMA 294, 2879-2888. Breslin FC, Day D, Tompa E, Irvin E, Bhattacharyya S, Clarke J, Wang A, 2007a. Non-agricultural work injuries among youth: a systematic review. Am J Prev Med 32, 151-162.

Breslin FC, Smith P, Dunn J, 2007b. An ecological study of regional variation in work injuries among young workers. BMC Public Health 7, 91.

Castillo-Riquelme M, Chalabi Z, Lord J, Guhl F, CampbellLendrum D, Davies C, Fox-Rushby J, 2008. Modelling geographic variation in the cost-effectiveness of control policies for infectious vector diseases: the example of Chagas disease. J Health Econ 27, 405-426.

Chen Y, Yi Q, Mao Y, 2008. Cluster of liver cancer and immigration: a geographic analysis of incidence data for Ontario 1998-2002. Int J Health Geog 7, 28.

Cinnamon J, Rinner C, Cusimano MD, Marshall S, Bekele T, Hernandez T, Glazier RH, Chipman ML. Online map design for public health decision-makers. Cartographica 44 , in press.

Crighton EJ, Elliott SJ, Kanaroglou P, Moineddin R, Upshur REG, 2008. Spatio-temporal analysis of pneumonia and influenza hospitalizations in Ontario, Canada. Geospat Health 2, 191-202.

Cromley EK, McLafferty SL, 2003. GIS and public health, Guildford, $340 \mathrm{pp}$.

Curtis S, 2004. Health and inequality, SAGE, 344 pp.

Detmer D, 2003. Building the national health information infrastructure for personal health, health care services, public health, and research. BMC Med Inform Decis Mak 3, 1.

Dunlop S, Coyte PC, McIsaac W, 2000. Socio-economic status and the utilisation of physicians' services: results from the Canadian National Population Health Survey. Soc Sci Med 51, 123-133.

Forjuoh SN, 2006. Burns in low and middle-income countries: a review of available literature on descriptive epidemiology, risk factors, treatment, and prevention. Burns 32, 529-537.

Friede A, Blum HL, McDonald M, 1995. Public health informatics - how information age technology can strengthen public health. Ann Rev Public Health 16, 239-252.

Griffin AL, MacEachren AM, Hardisty F, Steiner E, Li B, 2006. A comparison of animated maps with static smallmultiple maps for visually identifying space-time clusters. Ann Assoc Am Geog 96, 740-753.
Guidotti TL, 1995. Occupational injuries in Alberta: responding to recent trends. Occup Med 45, 81-88.

Hedley NR, 2001. Virtual and augmented reality interfaces: empirical findings and implications for spatial visualization. Paper presented at the 20th International Cartographic Conference, 6-10 August 2001, Beijing, China.

Hou F, Myles J, 2005. Neighbourhood inequality, neighbourhood affluence and population health. Soc Sci Med 60, 1557-1569.

Houez JP, Joly MF, Rannou A, Bussiere Y, Bourbeauj R, 1991. Geographical variations of motor-vehicle injuries in Québec, 1983-1988. Soc Sci Med 33, 15-21.

Jaspers MW, Steen T, van den Bos C, Geenen M, 2004. The think aloud method: a guide to user interface design. Int $\mathrm{J}$ Med Inform 73, 781-785.

Johnson CM, Johnson TR, Zhang J, 2005. A user-centered framework for redesigning health care interfaces. J Biomed Inform 38, 75-87.

Kamadjeu R, Tolentino H, 2006. Web-based public health geographic information systems for resources-constrained environment using scalable vector graphics technology: a proof of concept applied to the expanded program on immunization data. Int J Health Geog 5, 24.

Kossoulakou A, Kraak MJ, 1992. Spatio-temporal maps and cartographic communication. Cartogr J 29, 101-108.

Kukafka R, Yasnoff WA, 2007. Public health informatics. J Biomed Inform 40, 365-369.

Kushniruk A, 2002. Evaluation in the design of health information systems: application of approaches emerging from usability engineering. Comput Biol Med 32, 141-149.

Kushniruk AW, Patel VL, 2004. Cognitive and usability engineering methods for the evaluation of clinical information systems. J Biomed Inform 37, 56-76.

LaScala EA, Gerber D, Gruenewald PJ, 2000. Demographic and environmental correlates of pedestrian injury collisions: a spatial analysis. Accid Anal Prev 32, 651-658.

Lemstra M, Neudorf C, Opondo J, 2006. Health disparity by neighbourhood income. Can J Public Health 97, 435-439.

Maclachlan JC, Jerrett M, Abernathy T, Sears M, Bunch MJ, 2007. Mapping health on the Internet: a new tool for environmental justice and public health research. Health Place 13, 72-86.

Moshiro C, Heuch I, Åstrøm AN, Setel P, Hemed Y, Kvåle G, 2005. Injury morbidity in an urban and a rural area in 
Tanzania: an epidemiological survey. BMC Public Health 5, 11.

Nivala A-M, Sarjakoski LT, Sarjakoski T, 2007. Usability methods' familiarity among map application developers. Int J Hum Comput Stud 65, 784-795.

Norman KL, Panizzi E, 2006. Levels of automation and user participation in usability testing. Interact Comput 18, 246264.

Peterson MP, 2003. Maps and the Internet, Elsevier, 471 pp.

Petridou E, Tursz A, 2001. Socio-economic differentials in injury risk. Inj Control Safe Promot 8, 139-142.

Pevalin DJ, 2007. Socio-economic inequalities in health and service utilization in the London borough of Newham. Public Health 121, 596-602.

Pfeiffer C, Glaser S, Vencatesan J, Schliermann-Kraus E, Drescher A, Glaser R, 2008. Facilitating participatory multilevel decision-making by using interactive mental maps. Geospat Health 3, 103-112.

Platt S, Micciolo R, Tansella M, 1992. Suicide and unemployment in Italy: description, analysis and interpretation of recent trends. Soc Sci Med 34, 1191-1201.

Public Health Agency of Canada, 2007. GIS for Public Health Practice. August 12, 2007, from http://www.phacaspc.gc.ca/php-psp/gis-eng.php

Reimers A-M, de Leon A, Laflamme L, 2008. The area-based social patterning of injuries among 10 to 19 year olds Changes over time in the Stockholm County. BMC Public Health 8, 131.

Robinson AC, Chen J, Lengerich EJ, Meyer HG, MacEachren AM, 2005. Combining usability techniques to design geovisualization tools for epidemiology. CaGIS 32, 243-255.

Schuurman N, Cinnamon J, Crooks VA, Hameed SM, 2009. Pedestrian injury and the built environment: an environmental scan of hotspots. BMC Public Health 9, 233.

Scoggins A, Kjellstrom T, Fisher G, Connor J, Gimson N, 2004. Spatial analysis of annual air pollution exposure and mortality. Sci Total Environ 321, 71-85.

Slocum TA, Blok C, Jiang B, Koussoulakou A, Montello DR,
Fuhrmann S, Hedley NR, 2001. Cognitive and usability issues in geovisualization. CaGIS 30, 299-317.

Slocum TA, Cliburn DC, Feddema JJ, Miller JR, 2003. Evaluating the usability of a tool for visualizing the uncertainty of the future global water balance. CaGIS 30, 299-317. Slocum TA, Sluter RS, Kessler EC, Yoder SC, 2004. A qualitative evaluation of MapTime, a program for exploring spatiotemporal point data. Cartographica 39, 43-68.

Timpka T, Olvander C, Hallberg N, 2008. Information system needs in health promotion: a case study of the safe community programme using requirements engineering methods. Health Inform J 14, 183-193.

Tinetti ME, Baker DI, McAvay G, Claus EB, Garrett P, Gottschalk M, Koch ML, Trainor K, Horwitz RI, 1994. A multifactorial intervention to reduce the risk of falling among elderly people living in the community. New Engl J Med 331, 821-827.

Wang XY, Hu WB, Tong SL, 2009. Long-term exposure to gaseous air pollutants and cardio-respiratory mortality in Brisbane, Australia. Geospat Health 3, 257-263.

Yasnoff WA, O'Carroll PW, Koo D, Linkins RW, Kilbourne EM, 2000. Public health informatics: improving and transforming public health in the information age. J Public Health Manag Pract 6, 67-75.

Yiannakoulias N, Rowe BH, Svenson LW, Schopflocher DP, Kelly K, Voaklander DC, 2003. Zones of prevention: the geography of fall injuries in the elderly. Soc Sci Med 57, 2065-2073.

Younus M, Hartwick E, Siddiqi A, Wilkins M, Davies H, Rahbar M, Funk J, Saeed M, 2007. The role of neighborhood level socioeconomic characteristics in Salmonella infections in Michigan (1997-2007): assessment using geographic information system. Int J Health Geog 6, 56.

Zhang J, McKeown RE, Hussey JR, Thompson SJ, Woods JR, 2005. Gender differences in risk factors for attempted suicide among young adults: findings from the third national health and nutrition examination survey. Ann Epidemiol 15, 167-174. 